\title{
Treadmill Exercise Promotes Cyclic Alterations in Coronary Blood Flow in Dogs with Coronary Artery Stenoses and Endothelial Injury
}

\author{
John F. Eidt, Juliet Ashton, Paolo Golino, Janice McNatt, L. Maximilian Buja, and James T. Willerson \\ Departments of Medicine (Cardiology Division), Pathology, and Surgery at the University of Texas \\ Southwestern Medical Center at Dallas, Dallas, Texas 75235
}

\begin{abstract}
We have previously shown in anesthetized, open-chest dogs with coronary stenosis and endothelial injury that serotonin and/or thromboxane $\mathbf{A}_{2}\left(\mathrm{TXA}_{2}\right)$ receptor activation play a major role in the mediation of platelet-dependent, intermittent coronary occlusion. Using a similar model in awake, closedchest dogs, we tested the following hypotheses: $(a)$ treadmill exercise promotes the development of cyclic flow variations in dogs with coronary stenoses and endothelial injury; (b) ventricular pacing does not induce cyclic flow variations in the same dogs; and (c) $\mathrm{TXA}_{2}$ and/or serotonin are important mediators of exercise-induced cyclic flow variations in this model. The surgical preparation consisted of the application of a hard, flow-limiting constrictor and a Doppler ultrasonic flow probe around the left coronary artery of 11 dogs. Treadmill exercise resulted in the prompt development of cyclic flow variations in all 11 dogs. Ventricular pacing at rates as high as 170 beats/ min induced cyclic flow variations in only one of five dogs. Exercise-induced cyclic flow variations were abolished by TXA $\mathbf{A}_{2}$ and/or serotonin receptor antagonists in all but one dog. Thus, (a) treadmill exercise promotes the development of cyclic flow variations in dogs with coronary stenoses and endothelial injury; (b) ventricular pacing does not induce cyclic flow variations in most dogs in the same model; and (c) TXA and/ or serotonin are important mediators of cyclic flow variations in this model.
\end{abstract}

\section{Introduction}

Platelet-mediated obstruction of stenotic coronary arteries may be an important mechanism in certain occlusive coronary disease states (1-8). We have previously demonstrated that serotonin (9-11) and thromboxane $\mathrm{A}_{2}\left(\mathrm{TXA}_{2}\right)(12-14)$ are important mediators of coronary occlusion due to platelet aggregation in anesthetized dogs with coronary artery stenoses and endothelial injury. Other factors may be important in governing the process of platelet aggregation at sites of coronary artery stenosis in awake, active animals. Although it is clear from in vitro studies of platelet aggregation that platelet agonists can act synergistically (15), it is not known how frequently such mechanisms are functional in vivo $(11,16)$. It has

Address reprint requests to Dr. James T. Willerson, Cardiology Division, Room L5.134, University of Texas Southwestern Medical Center, 5323 Harry Hines Boulevard, Dallas, TX 75235.

Received for publication 4 October 1988 and in revised form 27 March 1989.

J. Clin. Invest.

(c) The American Society for Clinical Investigation, Inc.

$0021-9738 / 89 / 08 / 0517 / 11 \quad \$ 2.00$

Volume 84, August 1989, 517-527 been shown in humans that circulating levels of catecholamines and $\mathrm{TXB}_{2}$, the stable metabolite of TXA during periods of controlled exercise (17). Circulating markers of platelet activation, platelet factor 4 and $\beta$ thromboglobulin, have been shown to be elevated during periods of exercise-induced myocardial ischemia (18). Other investigators, however, have failed to substantiate a link between exercise and platelet activation in patients with coronary disease (19). Thus, it was our objective to evaluate the effect of exercise on the induction of platelet aggregation and cyclical reductions in coronary blood flow in dogs with coronary artery stenoses and endothelial injury.

In the animal model that we used, described originally by Folts et al. (20), a hard, plastic constrictor is placed around a canine coronary artery at the site of an induced endothelial injury. Within a few minutes, a unique pattern of coronary blood flow develops, characterized by severe, spontaneous reductions followed by abrupt, spontaneous restorations of flow. These recurrent reductions in coronary blood flow have been termed "cyclic flow variations" (CFVs) 1 and have been shown to result, at least in part, from the aggregation and subsequent dislodgement of occlusive platelet thrombi $(3,12,21)$. Agents specifically designed to inhibit platelet function, including serotonin receptor antagonists (9-11), TXA 2 synthesis inhibitors (12) or receptor antagonists (13), or MAbs to the platelet glycoprotein IIb/IIIa receptor (22), prevent the occurrence of CFVs in most cases. Furthermore, histologic examination of coronary arteries obtained at the nadir of cyclic flow variations consistently reveals an adherent platelet mass $(12,14,20)$. Using this platelet-dependent canine model, we tested the following hypotheses: $(a)$ that treadmill exercise promotes the development of CFVs in dogs with coronary stenoses and endothelial injury; $(b)$ that ventricular pacing does not induce cyclic flow variations in the same dogs; and (c) $\mathrm{TXA}_{2}$ and/or serotonin are important mediators of exercise-induced CFVs in this model.

\section{Methods}

11 mongrel dogs of either sex, weighing $20-40 \mathrm{~kg}$ were anesthetized with sodium pentobarbital $(30 \mathrm{mg} / \mathrm{kg})$ and ventilated with a mechanical respirator (Harvard Apparatus Co., S. Natick, MA). A heating pad was used to maintain rectal temperature at $38^{\circ} \mathrm{C}$. Under sterile conditions, a left fifth intercostal space thoracotomy was performed. A heparinized, polyethylene catheter was inserted into the descending thoracic aorta to provide direct arterial access and to measure blood pressure. A second catheter was inserted into the right atrium to provide central venous access. The heart was suspended in a pericardial cradle and a 2-cm segment of the left anterior descending (LAD) coronary artery was gently circumferentially isolated. A Doppler ultrasonic flow

1. Abbreviations used in this paper: CFV, cyclic flow variations; LAD, left anterior descending artery; TX, thromboxane. 
probe (Hartley Instruments Co., Houston, TX) (23) was placed around the proximal portion of the isolated LAD segment. Control values for heart rates and phasic and mean coronary; blood flows were recorded on an eight-channel recorder (model 7738, Hewlett Packard Co., Palo Alto, CA).

Experimental protocol. After control values for hemodynamics were obtained, the endothelium of the LAD was injured by gently squeezing the artery with a cushioned forceps (Fig. 1). A hard, plastic cylindrical constrictor was then placed around the LAD at the site of endothelial injury. The constrictor size was selected to reduce mean coronary artery blood flow by 10-20\%. CFVs usually developed within $15 \mathrm{~min}$ and were monitored for a period of at least $30 \mathrm{~min}$. The frequency of CFVs and the range of blood flow variation from peak to nadir was determined for a 30 -min period while the chest was open. Before termination of the surgical procedure, two ventricular pacing electrodes were sutured to the epicardial surfaces of the right ventricles in five dogs. The arterial and venous catheters, the Doppler lead wires, and the pacing wires were externalized and secured on the upper back. The chest was closed and hemodynamic monitoring continued in the operating suite for at least $1 \mathrm{~h}$ to ensure the proper functioning of all monitoring capabilities.

After the operation, all dogs were monitored continuously until recovery from the anesthetic was complete, usually 6-12 h. Subsequent to the immediate postoperative recovery period, care was taken to minimize the effect of data collection on normal recovery and physical activity. In five dogs, a stainless-steel fabric multi-channel umbilical monitoring cable (Alice King Chatham Medical Arts, Los Angeles, CA) was connected to the eight-channel recorder (model 7738; Hewlett-Packard Co.) to provide a continuous, uninterrupted record of the heart rates, blood pressures, and phasic and mean coronary blood flows. This cable was specially designed to allow normal physical activity and did not interfere with eating or sleeping. In six other dogs, monitoring was performed on a scheduled, periodic basis. These dogs were completely disconnected from the monitoring apparatus at night and were reconnected to the physiologic recorder up to three times a day for periods from 1 to $4 \mathrm{~h}$. Continuous monitoring was maintained during all episodes of CFVs or low flow states.

After recovery from the anesthetic was complete and the dogs were able to walk comfortably, each dog was entered into the following protocol designed to test the effect of $(a)$ ventricular pacing $(n=5)$ or (b) moderate treadmill exercise $(n=11)$ on the development of platelet-mediated coronary artery blood flow reduction.

Ventricular pacing. The effect of electrical ventricular pacing on the development of CFVs was tested in five dogs. Each dog was observed at rest for $15 \mathrm{~min}$ while control values for heart rates, blood pressures, and coronary blood flows were obtained (Fig. 1). The output of the ventricular pacemaker (model S-88 stimulator; Grassi Medical Instruments, Quincy, MA) was adjusted to maintain capture, and rates of $115,130,150$, and 170 beats/min were tested. Each rate was maintained for $5 \mathrm{~min}$ and then immediately increased to the next rate. Blood samples for plasma catecholamines were obtained during the control period and during the period of maximum pacing. Record was made of the blood pressures and coronary blood flows during each pacing period. During episodes of CFVs, the peak and nadir coronary blood flows were determined. After the pacemaker had been disconnected, the dogs were carefully monitored for at least $1 \mathrm{~h}$ to ensure the return of hemodynamic equilibrium before the initiation of treadmill exercise.

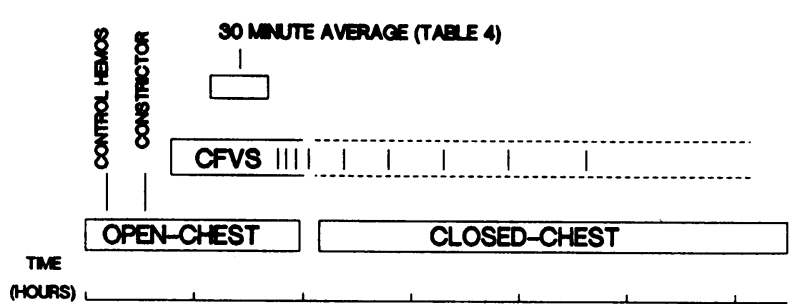

B

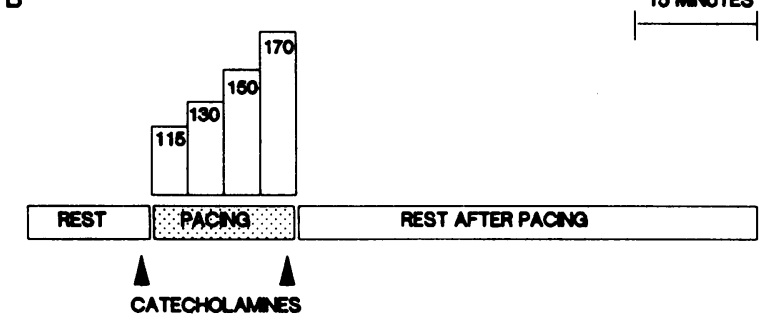

C

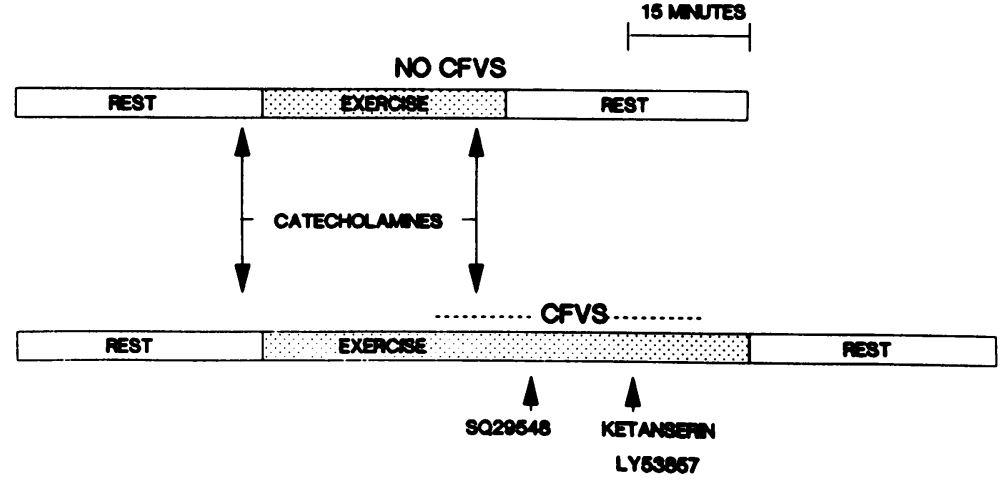

Figure 1. (A) Day of surgery. After stabilization, control hemodynamic values were recorded. The constrictor was placed around the LAD coronary artery to reduce coronary blood flow by $10-20 \%$. CFVs usually develop spontaneously within $15 \mathrm{~min}$ of placing the constrictor; the frequency of cyclic flow variations in 30 min was determined. After chest closure, there was a gradual discontinuation of CFVs by $3 \mathrm{~h}$ postoperatively. $(B)$ Ventricular pacing. After a control period at rest, ventricular pacing was sequentially tested at rates of $115,130,150$, and 170 beats/minute ( 5 min at each rate). The development of CFVs before, during, and after pacing was noted. Plasma catecholamine levels were determined during control and maximum pacing. $(C)$ Treadmill exercise. After 30 min at rest, control values for heart rates, blood pressures and plasma catecholamines were determined. The treadmill was started and maintained at $1 \mathrm{mph}$ for $30 \mathrm{~min}$. If CFVs occurred (bottom), exercise was continued while treatment with a TXA $\mathrm{T}_{2}$ receptor antagonist (SQ295Y8) and/or serotonin receptor antagonist (ketanserin or LY53857), was given. Exercise was continued at least 15 min after drug administration. 
Exercise protocol. After recovery from the surgical procedure was complete and dogs were able to walk comfortably, the effect of treadmill exercise on the development of cyclic flow variations was tested in 11 dogs (Fig. 1). Each dog was monitored at rest for $30 \mathrm{~min}$ while standing on a specially modified treadmill (Landace Treadmill Co., Dover, NJ). Baseline values for heart rates, blood pressures, and phasic and mean coronary blood flows were recorded. All dogs had stable, nonvarying coronary blood flows before exercise. At the end of $30 \mathrm{~min}$ at rest, blood samples for the determination of plasma catecholamines were obtained from the arterial catheter. The treadmill was then started at 1-2 mph and maintained at this rate for $30 \mathrm{~min}$. A period of treadmill exercise was designated as the time that the treadmill was in operation. The maximum heart rates, blood pressures, and coronary blood flows during treadmill exercise were recorded. If CFVs did not occur during the 30-min period of treadmill exercise, the treadmill was stopped and observation continued at rest for $30 \mathrm{~min}$. If CFVs were observed, treadmill exercise was continued while either a serotonin or $\mathrm{TXA}_{2}$ receptor antagonist was administered (see protocol below). The severity (nadir coronary blood flow) and frequency of CFVs was determined before and after treatment. A blood sample for catecholamine determination was obtained at the time CFVs developed or at the end of exercise, if CFVs did not occur.

Treatment of exercise-induced CFVs. To test the importance of serotonin, thromboxane $A_{2}$ and/or alpha $a_{2}$-adrenergic receptor activation in the mediation of platelet-dependent reductions in coronary blood flow in awake, closed-chest, exercising dogs with coronary artery stenoses, we entered six dogs into the following treatment protocol. Exercise-induced CFVs were observed for 15 min while exercise continued to ensure the persistence of the altered flow state. Each dog was then randomly assigned to receive a drug from one of the following treatment groups.

Group I: serotonin $S_{2}$ receptor antagonists. Either the serotonin $\mathrm{S}_{2}$ receptor antagonist, ketanserin (24-26) (Janssen Pharmaceuticals, Beerse, Belgium) $(0.25 \mathrm{mg} / \mathrm{kg})$ or LY53857 $(27,28)$ (Eli Lilly Co., Indianapolis, IN) $(0.1 \mathrm{mg} / \mathrm{kg})$, a more highly selective serotonin receptor antagonist, was administered as an intravenous bolus while exercise-induced CFVs continued. The effect of treatment with ketanserin or LY53857 on the frequency and severity (nadir) of CFVs was determined. If CFVs were not abolished or coronary flow did not return to at least $70 \%$ of control within $5 \mathrm{~min}$, an additional dose of the same drug was given. If the additional dose was not effective, a TXA $2 / \mathrm{PGH}_{2}$ receptor antagonist was administered according to the protocol below. After drug administration, exercise was continued for $15 \mathrm{~min}$ followed by a 1-h period of observed recuperation.

Group II: $\mathrm{TXA}_{2} / \mathrm{PGH}_{2}$ receptor antagonist. To test the role of $\mathrm{TXA}_{2}$ in mediating coronary blood flow reductions in awake, exercising dogs, the receptor antagonist, SQ29548 (29) (Squibb Institute for Medical Research, Princeton, NJ) $(0.25 \mathrm{mg} / \mathrm{kg})$, was administered as an intravenous bolus during exercise-induced CFVs or persistent low flow. An additional dose was administered if the initial dose did not abolish CFVs or improve coronary blood flow to at least $70 \%$ of control within
5 min. If the additional dose was not effective in abolishing CFVs, a serotonin receptor antagonist was added to test the effect of the combination of a $\mathrm{TXA}_{2} / \mathrm{PGH}_{2}$ receptor antagonist and a serotonin receptor antagonist. After drug administration, exercise was continued for 15 min followed by a 1-h period of observed recuperation.

Group III: alpha ${ }_{2}$-adrenergic receptor inhibition. The alpha ${ }_{2}-$ adrenergic receptor antagonist, yohimbine (30) (Sigma Chemical Co., St. Louis, MO) $(1.0 \mathrm{mg} / \mathrm{kg})$, was administered as an intravenous bolus during exercise-induced reductions in coronary blood flow. The effect of yohimbine on CFVs or persistent low flow was recorded as described previously for other agents. An additional dose was administered if the initial dose was unsuccessful. Exercise was continued for $15 \mathrm{~min}$ after drug administration and recuperation was observed for at least $1 \mathrm{~h}$.

Plasma catecholamines. Blood samples for the determination of plasma epinephrine and norepinephrine were obtained from the arterial catheter and immediately centrifuged and the serum was separated. Plasma samples were analyzed using HPLC (Smith-Kline Biosciences, St. Louis, MO).

Statistical analyses. All values are expressed as the mean \pm SEM. The effect of ventricular pacing was analyzed using an analysis of variance with a correction for repeated measures. Values obtained before and after exercise and treatment were compared with a paired $t$ test. Independent groups were compared with an unpaired $t$ test. A general linear model procedure was used in the analysis of variables predictive of the development of CFVs in a given dog during pacing or exercise. A $P$ value $<0.05$ was considered significant.

\section{Results}

11 consecutive dogs underwent the initial operative procedure and all survived. The intraoperative heart rates, blood pressures, and coronary blood flows are recorded in Table $I$. The placement of the cylindrical constrictor around the left anterior descending coronary artery resulted in a 19\% decrease in mean coronary blood flow, but it was not associated with any significant change in the heart rates or blood pressures. All 11 dogs developed spontaneous CFVs in the operating room. During CFVs in anesthetized, open-chest dogs, the mean coronary blood flow ranged from $98 \pm 5 \%$ control (peak) to $46 \pm 4 \%$ (nadir) at a frequency of $7.2 \pm 0.4$ cycles per $30 \mathrm{~min}$. After chest closure, all dogs experienced the gradual discontinuation of cyclic flow variations by $3 \mathrm{~h}$ after operation. The average coronary blood flow on the morning of the first postoperative day after stabilization was $94 \pm 8 \%$ of control.

Ventricular pacing. The effect of ventricular pacing was tested in 5 of 11 dogs (Table II). There was a significant increase in phasic and mean coronary blood flow during maximal pacing. There was no significant increase in blood pres-

Table I. Intraoperative Hemodynamics in Anesthetized, Open-chest Dogs $(n=11)$

\begin{tabular}{|c|c|c|c|c|c|c|c|c|}
\hline & \multirow[b]{2}{*}{ Heart rate } & \multirow[b]{2}{*}{ AOS } & \multirow[b]{2}{*}{ AOD } & \multicolumn{2}{|c|}{ Phasic flow } & \multicolumn{2}{|c|}{ Mean flow } & \multirow[b]{2}{*}{ Frequency } \\
\hline & & & & Peak & Nadir & Peak & Nadir & \\
\hline & beats/min & & & & & & & (CFVs per $30 \mathrm{~min})$ \\
\hline Control & $138 \pm 4$ & $138 \pm 6$ & $91 \pm 4$ & 100 & & 100 & & 0 \\
\hline Sten & $138 \pm 4$ & $133 \pm 5$ & $90 \pm 4$ & $79 \pm 5^{*}$ & & $81 \pm 4^{*}$ & & 0 \\
\hline CFVs & $137 \pm 4$ & $134 \pm 6$ & $90 \pm 3$ & $96 \pm 5$ & $45 \pm 4^{\ddagger}$ & $98 \pm 5$ & $46 \pm 4^{\ddagger}$ & $7.2 \pm 0.4^{*}$ \\
\hline
\end{tabular}

AOS, arterial systolic pressure; AOD, arterial diastolic pressure; Peak, maximum coronary blood flow; Nadir, minimum coronary blood flow during CFVs; Sten, time period after placement of coronary constrictor; CFVs, period of cyclic flow variations. ${ }^{*} P<0.05$ vs control; ${ }^{\ddagger} P$ $<0.05$ sten vs. CFVs. 
Table II. Hemodynamics and Plasma Catecholamine Levels during Ventricular Pacing in Awake, Unsedated Dogs with Coronary Artery Stenoses and Endothelial Injury $(n=5)$

\begin{tabular}{|c|c|c|c|c|c|c|c|c|c|}
\hline & \multirow[b]{2}{*}{ Heart rate } & \multirow[b]{2}{*}{ AOS } & \multirow[b]{2}{*}{ AOD } & \multicolumn{2}{|c|}{ Phasic flow } & \multicolumn{2}{|c|}{ Mean flow } & \multirow[b]{2}{*}{ EPI } & \multirow[b]{2}{*}{$\mathrm{NE}$} \\
\hline & & & & Peak & Nadir & Peak & Nadir & & \\
\hline & beats/min & \multicolumn{2}{|c|}{$\mathrm{mmHg}$} & \multicolumn{4}{|c|}{$\%$ control } & \multicolumn{2}{|c|}{$p g / m l$} \\
\hline Control & $98 \pm 7$ & $105 \pm 3$ & $69 \pm 2$ & $73 \pm 1$ & & $87 \pm 13$ & & $89 \pm 22$ & $259 \pm 92$ \\
\hline Pace 115 & 115 & $103 \pm 3$ & $73 \pm 2$ & $75 \pm 1^{*}$ & & $93 \pm 14^{*}$ & & & \\
\hline Pace 130 & $130^{*}$ & $104 \pm 4$ & $73 \pm 3$ & $78 \pm 11^{*}$ & & $94 \pm 14^{*}$ & & & \\
\hline Pace 150 & $150^{*}$ & $101 \pm 3$ & $73 \pm 3$ & $72 \pm 8$ & & $101 \pm 15^{*}$ & & & \\
\hline Pace 170 & $170^{*}$ & $101 \pm 3$ & $74 \pm 2$ & $99 \pm 15^{*}$ & $68^{\ddagger}$ & $116 \pm 18^{*}$ & $74^{\ddagger}$ & $77 \pm 64$ & $220 \pm 91$ \\
\hline Post & $98 \pm 6$ & $106 \pm 3$ & $75 \pm 3$ & $71 \pm 10$ & & $82 \pm 13$ & & & \\
\hline
\end{tabular}

During the control period, and during pacing at 115, 130, and $150 \mathrm{~min}$ and during the postpacing period, there were no significant variations in coronary blood flow and therefore a nadir flow value was not recorded; EPI, plasma epinephrine; NE, plasma norepinephrine; PACE, ventricular pacing rates per minute; POST, 15 min after pacing; ${ }^{*} P<0.05$ vs. control, ANOVA with correction for repeated measures; ${ }^{\ddagger}$ nadir coronary blood flow in one dog that developed CFVs during ventricular pacing. For other abbreviations, see Table I.

sure during ventricular pacing. There was no significant change in the plasma epinephrine levels during maximal pacing (Fig. 2) $(89 \pm 22$ vs. $77 \pm 64 \mathrm{pg} / \mathrm{ml}, P=\mathrm{NS}, n=5)$. Only one dog developed CFVs during ventricular pacing (Fig. 3). At a maximal rate of 170 beats/min, this dog developed mild, though frequent, CFVs that completely disappeared when the rate was decreased to 150 beats/min. None of the other four dogs that were tested developed CFVs during any of 11 periods of ventricular pacing.

Effect of exercise. The effect of treadmill exercise on coronary blood flow, hemodynamics, and plasma catecholamines was tested in 11 dogs (Table III). During the control period at rest, no spontaneous reductions in coronary blood flow were observed. Resting plasma epinephrine levels were not significantly different from dogs before pacing (102 \pm 47 vs. $89 \pm 22$ $\mathrm{pg} / \mathrm{ml}, P=\mathrm{NS})$. Treadmill exercise at $1-2 \mathrm{mph}$ was associated with a significant increase in heart rates $(123 \pm 5$ to $153 \pm 6, P$ $=0.001)$, systolic blood pressures $(122 \pm 3$ to $137 \pm 2 \mathrm{mmHg}, P$ $=0.05)$, and maximal coronary blood flow $(97 \pm 6$ to $125 \pm 8 \%$

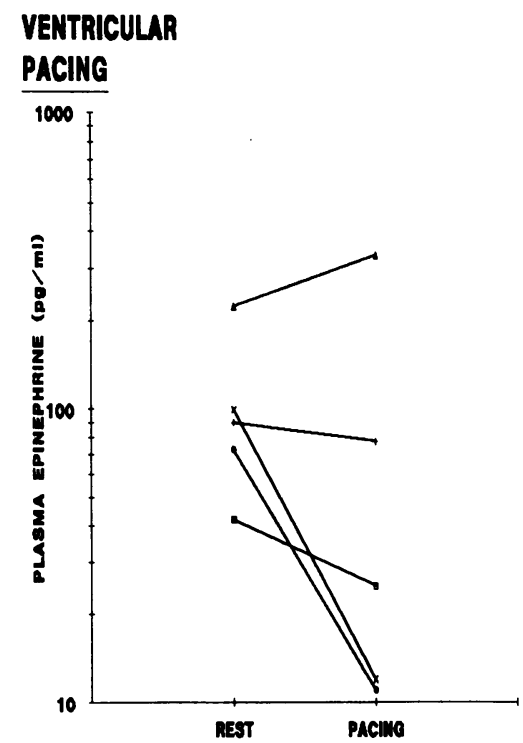

Figure 2. The plasma epinephrine levels obtained before and during ventricular pacing at 170 beats $/ \mathrm{min}$ in awake, resting dogs are shown. Each line represents one dog. Plasma epinephrine levels decreased during ventricular pacing in four of five dogs tested. There was no significant change in the mean epinephrine level during ventricular pacing $(89 \pm 82$ vs. $77 \pm 64, P=$ NS by paired $t$ test $)(n=5)$. control, $P=0.02$ ). During 17 of 34 periods of treadmill exercise, all 11 dogs developed severe reductions in coronary blood flow during treadmill exercise (Fig. 4). CFVs occurred during

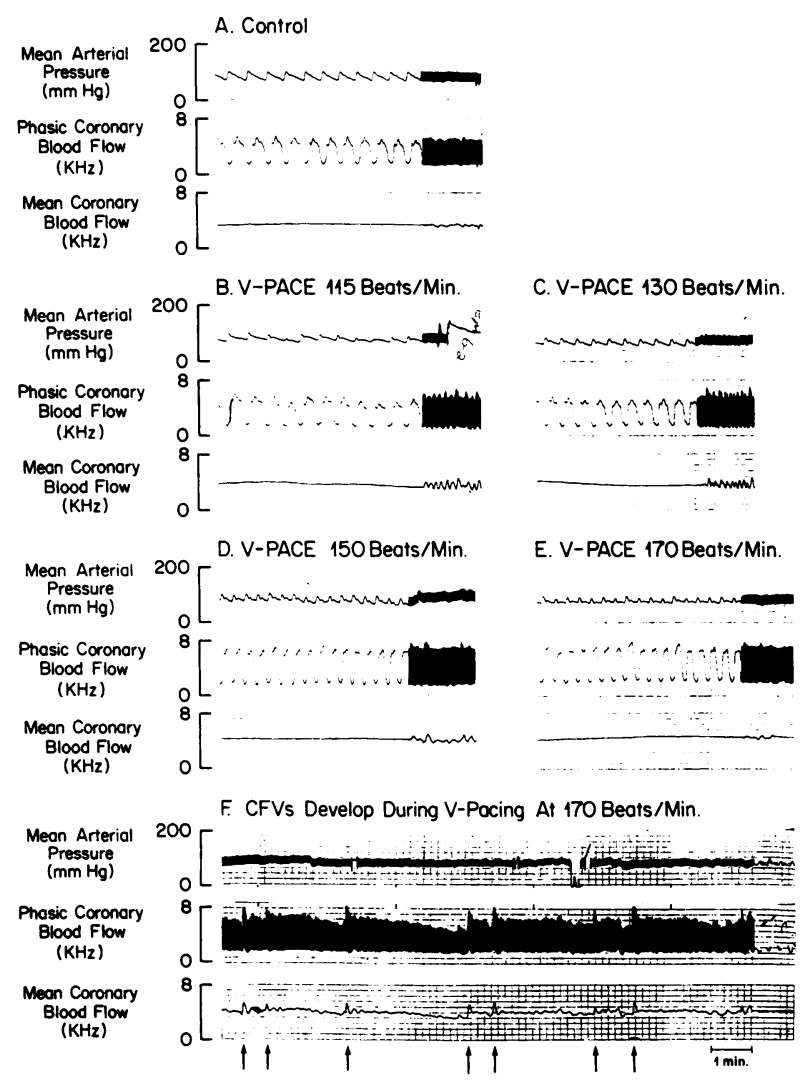

Figure 3. The effect of ventricular pacing on the development of CFVs in a dog with coronary artery stenosis and endothelial injury is shown. The mean arterial pressure and phasic and mean coronary blood flows at rest are shown in $A$. Ventricular pacing at rates of $(B)$ $115,(C) 130,(D) 150$, and $(E) 170$ beats/min were tested. After 15 $\mathrm{min}$ at a rate of $(F) 170$ beats/min, this dog developed frequent ( $18 / 30 \mathrm{~min}$ ), though mild, CFVs (mean nadir flow $=74 \%$ control). The CFVs disappeared when the pacing rate was decreased to 150 beats/min. 
Table III. Hemodynamics and Plasma Catecholamine Levels during Treadmill Exercise in Awake, Unsedated Dogs with Coronary Artery Stenoses and Endothelial Injury $(n=11)$

\begin{tabular}{|c|c|c|c|c|c|c|c|c|c|}
\hline & \multirow[b]{2}{*}{ Heart rate } & \multirow[b]{2}{*}{ AOS } & \multirow[b]{2}{*}{ AOD } & \multicolumn{2}{|c|}{ Phasic flow } & \multicolumn{2}{|c|}{ Mean flow } & \multirow[b]{2}{*}{ EPI } & \multirow[b]{2}{*}{$\mathrm{NE}$} \\
\hline & & & & Peak & Nadir & Peak & Nadir & & \\
\hline & beats/min & \multicolumn{2}{|c|}{$m m H g$} & \multicolumn{4}{|c|}{ \% control } & \multicolumn{2}{|c|}{$p g / m l$} \\
\hline Control & $123 \pm 5$ & $122 \pm 3$ & $83 \pm 2$ & $88 \pm 6$ & & $97 \pm 6$ & & $102 \pm 47$ & $326 \pm 102$ \\
\hline Exercise & $153 \pm 6^{*}$ & $137 \pm 2^{*}$ & $85 \pm 2$ & $114 \pm 7^{*}$ & $31 \pm 12^{*}$ & $125 \pm 8^{*}$ & $30 \pm 12^{*}$ & $266 \pm 105^{*}$ & $751 \pm 144^{*}$ \\
\hline
\end{tabular}

Control, during 30-min rest period before treadmill exercise; exercise, treadmill exercise at 1-2 mph. For dogs tested more than once, results are averaged within each dog before analysis; ${ }^{*} P<0.05$ vs. control. For other abbreviations, see Tables I and II.

the first period of treadmill exercise in only five dogs (45\%). In the other dogs, cyclic flow variations were first observed during the second $(n=4)$, third $(n=1)$, or seventh $(n=1)$ period of exercise testing. Once exercise-induced reductions in coronary blood flow had been observed, they invariably recurred during subsequent exercise periods in the same dog. During exerciseinduced CFVs, the mean coronary blood flow ranged from $125 \pm 8$ (peak) to $30 \pm 12 \%$ (nadir) of intraoperative control values at a frequency of $8.2 \pm 1.8$ cycles $/ 30 \mathrm{~min}$. In eight dogs, during one or more periods of treadmill exercise, CFVs deteriorated into a pattern of noncyclic persistent low coronary blood flow (mean flow $18 \pm 5 \%$ control) after an average of $6.0 \pm 1.2$ cycles. Plasma epinephrine levels increased significantly during treadmill exercise (Fig. 5). There was no difference between the plasma epinephrine levels during exercise periods when reductions in coronary blood flow occurred and when flow reductions did not occur $(256 \pm 85$ vs. $481 \pm 245$ $\mathrm{pg} / \mathrm{ml}, P=\mathrm{NS})$. The initial heart rates, blood pressures, plasma catecholamine levels, and the corresponding changes during exercise were not predictive of the development of CFVs in individual dogs. The occurrence of CFVs during previous periods of exercise was predictive of the subsequent development of exercise-induced CFVs.

Effect of treatment with a serotonin receptor antagonist or a $\mathrm{TXA}_{2} / \mathrm{PGH}_{2}$ receptor antagonist. A serotonin receptor antagonist (ketanserin or LY53857) and/or a $\mathrm{TXA}_{2} / \mathrm{PGH}_{2}$ receptor antagonist (SQ29548) was administered intravenously 17 times to six dogs during episodes of exercise-induced reductions in coronary blood flow (Tables IV-VI). The administration of SQ29548 (average dose $0.30 \pm 04 \mathrm{mg} / \mathrm{kg}$, range 0.2 to $0.4 \mathrm{mg} / \mathrm{kg})$, either as a single agent $(n=4)$ or in addition to a serotonin receptor antagonist $(n=4)$, during episodes of exercise-induced reductions in coronary blood flow resulted in a greater than twofold increase in mean coronary blood flow (35 \pm 10 to $80 \pm 18 \%$ control, $P=0.01, n=8$ ). In four dogs with CFVs (average peak/nadir flow 105 $\pm 12 / 50 \pm 15 \%$ control), SQ29548 resulted in a significant decrease in the frequency (7.75 \pm 1.1 vs. $2.5 \pm 1.5$ CFVs per $30 \mathrm{~min}, P=0.05, n=4)$ and severity (nadir flow increased to $87 \pm 28 \%$ control, $n=4$ ) of CFVs (Fig. 6). In three of four dogs in whom CFVs deteriorated into a noncyclic pattern of persistent low coronary blood flow, SQ29548 caused a marked increase in coronary blood flow ( $22 \pm 6$ to $74 \pm 27 \%$ control, $P=0.09, n=4)$. In one dog with persistent low flow on postoperative day 7 and in one dog with CFVs on postoperative day 11 despite treatment with ketanserin, SQ29548 failed to substantially improve coronary blood flow. Administration of SQ29548 was not associated with any significant changes in heart rates (146 \pm 13 vs. $149 \pm 14, P=\mathrm{NS}, n=8)$ or mean blood pressures $(94 \pm 8$ vs. $97 \pm 6, P=$ NS, $n=8$ ) (Table V).

The administration of a serotonin receptor antagonist, ketanserin ( $n=3$, average dose $0.42 \mathrm{mg} / \mathrm{kg}$, range 0.25 to 0.50 $\mathrm{mg} / \mathrm{kg}$ ) or LY53857 ( $n=6$, average dose $0.23 \pm 0.05$ range 0.2 to $0.4 \mathrm{mg} / \mathrm{kg}$ ), during episodes of exercise-induced reductions in coronary blood flow resulted in a significant increase in mean coronary blood flow ( $32 \pm 9$ to $49 \pm 13, P=0.03, n=9$ ) (Fig. 7). In four dogs with cyclic flow reductions (average peak/nadir mean flow $108 \pm 22 / 47 \pm 14 \%$ control), ketanserin $(n=1)$ or LY53857 $(n=3)$ resulted in a significant reduction in the frequency of CFVs $(6.25 \pm 0.55$ vs. $1.25 \pm 1.25, P=0.05$, $n=4$ ) and in their severity (nadir flow increased to $81 \pm 13 \%$ control, $P=0.07, n=4$ ). In two of five dogs with persistent

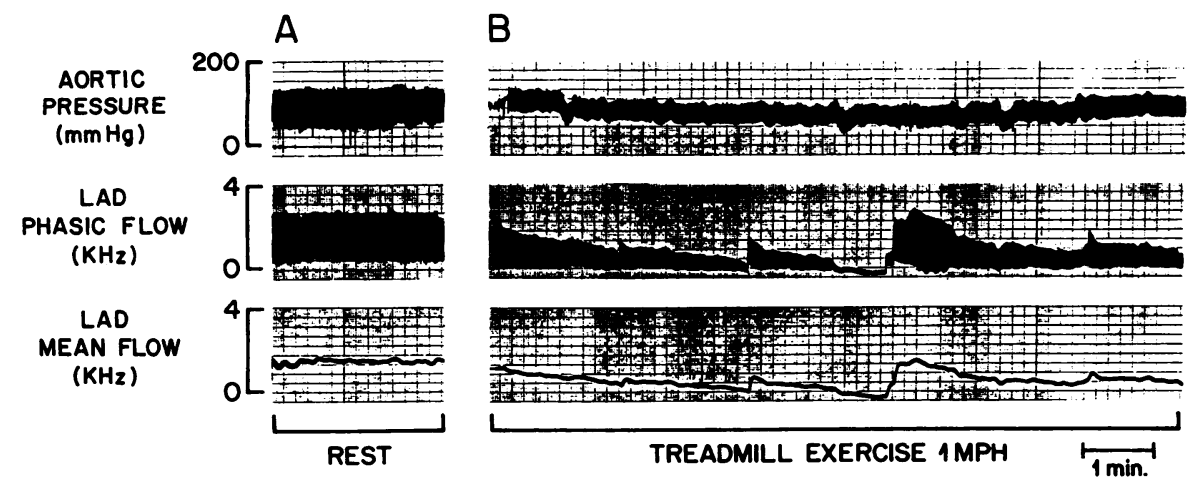

Figure 4. This physiologic recording shows the effect of treadmill exercise at $1 \mathrm{mph}$ on blood pressure (top) and phasic and mean coronary blood flow measured by Doppler flow probe $(\mathrm{kHz})$ in a dog with coronary artery stenosis and endothelial injury. At rest, coronary blood flow was stable ( $96 \%$ of intraoperative control) and without cyclic variation. After treadmill exercise for 11 minutes, a series of severe, spontaneous reductions in coronary blood flow was observed. In this case, discontinuation of treadmill exercise was followed by cessation of CFVs after 15 min (not shown). 


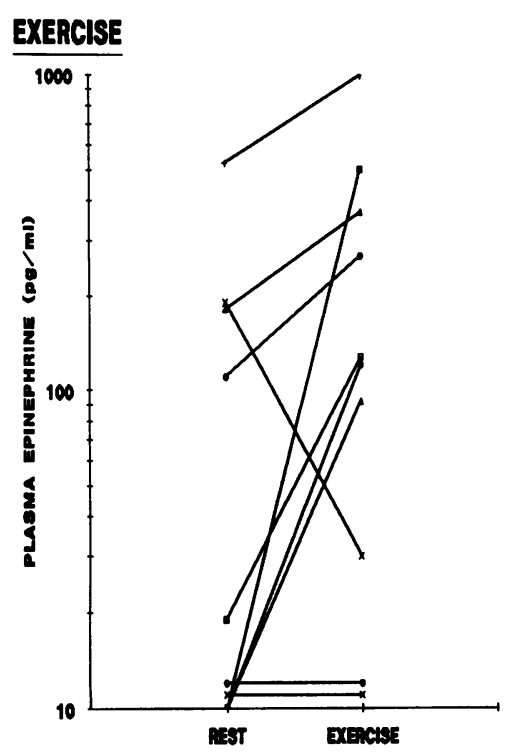

Figure 5. The plasma epinephrine levels obtained before and during treadmill exercise are shown for each dog $(n=11)$. For dogs exercised more than once, values are averaged within each dog before plotting. There was a significant increase in the mean plasma epinephrine levels during treadmill exercise $(102 \pm 47$ vs. $266 \pm 105$, $P<0.05$ paired $t$ test) $(n=11)$. There was no significant difference between epinephrine levels obtained before pacing versus treadmill exercise ( $89 \pm 22$ vs. $102 \pm 47, P=$ NS, unpaired $t$ test).

noncyclic low coronary blood flow, there was prompt increase in mean coronary blood flow subsequent to the administration of a serotonin receptor antagonist (ketanserin, one of one;
LY53857, one of four). If CFVs were abolished by a single agent, they did not recur during the same period of treadmill exercise.

In five cases, CFVs $(n=2)$ or low coronary flow $(n=3)$ persisted despite treatment with a serotonin receptor antagonist $(n=4)$ or a TXA $2 / \mathrm{PGH}_{2}$ receptor antagonist $(n=1)$. In two of three dogs with persistent low coronary blood flow after treatment with LY53857 (17 $\pm 7 \%$ control), the addition of SQ29548 resulted in a marked increase in coronary blood flow ( $78 \pm 37 \%$ control). In one of two dogs, the combination of SQ29548 and ketanserin successfully abolished CFVs during exercise. When the results of treatment of exercise-induced reductions in coronary blood flow with serotonin and/or $\mathrm{TXA}_{2} / \mathrm{PGH}_{2}$ receptor antagonists are pooled, the efficacy of therapy is pronounced (Fig. 8). In 9 of 12 (75\%) episodes of exercise-induced coronary flow reductions, either a single agent $(6$ of $7,86 \%)$ or the combination of a serotonin receptor antagonist and a $\mathrm{TXA}_{2}$ receptor antagonist ( 3 of $\left.5,60 \%\right)$ resulted in marked improvement in mean coronary blood flow ( $33 \pm 6$ vs. $64 \pm 11 \%$ control, $P=0.001, n=17$ ). CFVs were successfully abolished in five of six cases (83\%). Persistent low flow was improved in four of six cases but coronary blood flow increased to at least $70 \%$ control in only two. Thus, persistent low coronary flow was substantially less responsive to treatment with serotonin and/or thromboxane receptor antagonists than were CFVs $(P=0.05)$.

Table IV. Treatment of Exercise-induced Reductions in Canine Coronary Blood Flow: Serotonin Receptor Antagonist or TXA, Receptor Antagonist

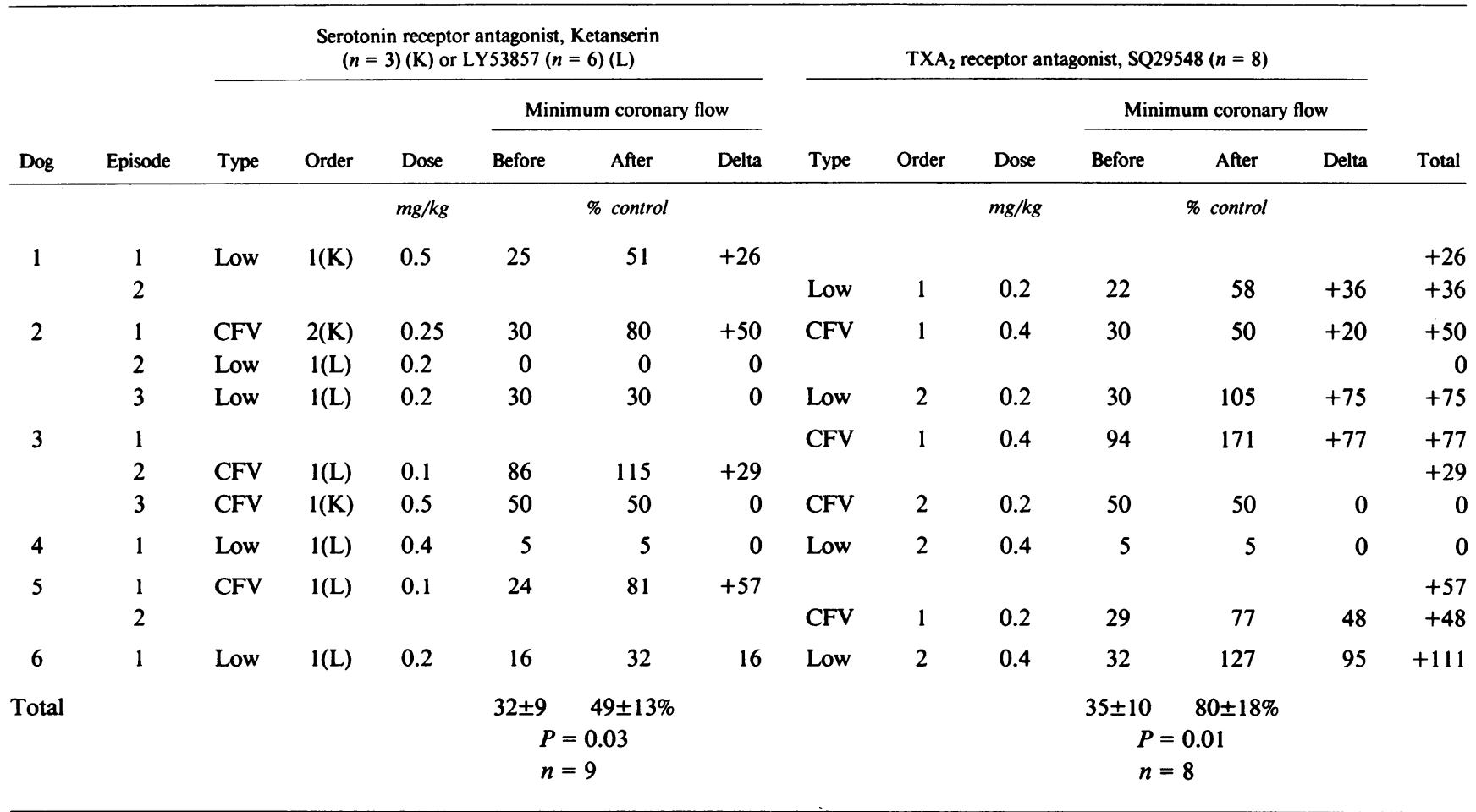

Treatment with a serotonin receptor antagonist and/or a $\mathrm{TXA}_{2} / \mathbf{P G H}_{2}$ receptor antagonist during exercise-induced reductions in coronary blood flow resulted in a twofold increase in minimum coronary blood flow ( $33 \pm 6$ to $64 \pm 11 \%$ control, $P=0.001, n=17)$. Episode, first, second, or third episode of exercise-induced reduction in coronary blood flow; type, CFV or low flow (Low); order, order of administration (1, first; 2 , second). If exercise-induced reduction in coronary flow was not improved by treatment with the first agent (two doses), then a second agent was added. Minimum coronary flow, lowest coronary blood flow (mean) recorded during either CFVs or persistent low flow; before/after, before and after treatment; delta, change in minimum coronary blood flow after treatment; total, cumulative increase in coronary blood flow after treatment with either one or two drugs. 
Table V. Effect of Treatment with a Serotonin Receptor Antagonist and/or a TXA $A_{2}$ Receptor Antagonist during Exercise-induced Reductions in Coronary Artery Blood Flow in Dogs with Coronary Stenoses

\begin{tabular}{ccccccc}
\hline Heart rate & AOS & AOD & Phasic peak & Phasic nadir & Mean peak & Mean nadir \\
\hline beats $/$ min & & $\mathrm{mmHg}$ & & \% control
\end{tabular}

Ketanserin (average dose $0.42 \pm 0.08 \mathrm{mg} / \mathrm{kg}$ )

\begin{tabular}{|c|c|c|c|c|c|c|c|}
\hline Before & $120 \pm 10$ & $122 \pm 2$ & $81 \pm 4$ & $77 \pm 24$ & $42 \pm 6$ & $80 \pm 20$ & $42 \pm 8$ \\
\hline$P$ & & & & & 0.3 & & 0.18 \\
\hline After & $126 \pm 7$ & $116 \pm 3$ & $75 \pm 3$ & $80 \pm 20$ & $68 \pm 13$ & $90 \pm 10$ & $60 \pm 10$ \\
\hline
\end{tabular}

LY53857 (average dose $0.23 \pm 0.05 \mathrm{mg} / \mathrm{kg}$ )

\begin{tabular}{|c|c|c|c|c|c|c|c|}
\hline Before & $156 \pm 18$ & $135 \pm 3$ & $81 \pm 1$ & $81 \pm 39$ & $24 \pm 12$ & $107 \pm 26$ & $27 \pm 13$ \\
\hline$P$ & & & & & 0.18 & & 0.12 \\
\hline After & $160 \pm 17$ & $139 \pm 6$ & $86 \pm 6$ & $77 \pm 29$ & $33 \pm 16$ & $98 \pm 17$ & $44 \pm 18$ \\
\hline
\end{tabular}

Ketanserin or LY53857

\begin{tabular}{|c|c|c|c|c|c|c|c|}
\hline Before & $144 \pm 14$ & $130 \pm 3$ & $81 \pm 1$ & $78 \pm 5$ & $30 \pm 9$ & $93 \pm 15$ & $32 \pm 9$ \\
\hline$P$ & 0.06 & & & & 0.07 & & 0.03 \\
\hline After & $148 \pm 13$ & $131 \pm 5$ & $82 \pm 5$ & $79 \pm 14$ & $45 \pm 12$ & $94 \pm 8$ & $49 \pm 13$ \\
\hline
\end{tabular}

SQ29548 (average dose $0.30 \pm 0.04 \mathrm{mg} / \mathrm{kg}$ )

$$
n=8
$$

$\begin{array}{cccccccc}\text { Before } & 146 \pm 13 & 135 \pm 5 & 87 \pm 3 & 95 \pm 27 & 30 \pm 8 & 121 \pm 28 & 35 \pm 10 \\ P \quad \text { After } & 149 \pm 14 & 134 \pm 7 & 89 \pm 4 & 89 \pm 23 & 69 \pm 17 & 100 \pm 26 & 80 \pm 18\end{array}$

All treatments

\begin{tabular}{|c|c|c|c|c|c|c|c|}
\hline$n=1$ & & & & & & & \\
\hline Before & $145 \pm 9$ & $132 \pm 3$ & $84 \pm 2$ & $87 \pm 15$ & $30 \pm 6$ & $107 \pm 16$ & $33 \pm 6$ \\
\hline$P$ & 0.11 & & & & 0.004 & & 0.001 \\
\hline After & $149 \pm 9$ & $133 \pm 4$ & $86 \pm 3$ & $84 \pm 36$ & $56 \pm 11$ & $97 \pm 13$ & $64 \pm 11$ \\
\hline
\end{tabular}

Before/after, treatment effect. The data for both serotonin receptor antagonists were pooled and recorded under the heading ketanserin or LY53857. During cases of persistent low flow, the same values were recorded for peak and nadir flows. $P<0.05$ significant, paired $t$ test. For other abbreviations, see Table I.

Table VI. Effect of Treatment on Frequency and Severity of CFVs and Persistent Low Flow in Exercising Dogs

\begin{tabular}{|c|c|c|c|c|c|c|}
\hline & \multicolumn{2}{|c|}{ Serotonin receptor antagonist } & \multicolumn{2}{|c|}{ Thromboxane receptor antagonist } & \multicolumn{2}{|c|}{ Total } \\
\hline & Before & After & Before & After & Before & After \\
\hline \multicolumn{7}{|l|}{ CFVs } \\
\hline Frequency & $6.75 \pm 1.25$ & $\begin{array}{c}1.25 \pm 1.25 \\
P=0.05 n=4\end{array}$ & $7.75 \pm 1.1$ & $\begin{array}{c}2.5 \pm 1.5 \\
P=0.05 n=4\end{array}$ & $7.83 \pm 0.77$ & $\begin{array}{c}0.83 \pm 0.83 \\
P=0.05 n=6\end{array}$ \\
\hline $\begin{array}{l}\text { Severity } \\
\text { (Nadir) }\end{array}$ & $47 \pm 14$ & $\begin{array}{c}81 \pm 13 \\
P=0.07 n=4\end{array}$ & $50 \pm 15$ & $\begin{array}{c}87 \pm 28 \\
P=0.11 n=4\end{array}$ & $52 \pm 9$ & $\begin{array}{c}84 \pm 15 \\
P=0.01 n=8\end{array}$ \\
\hline \multicolumn{7}{|l|}{ Low flow } \\
\hline $\begin{array}{l}\text { Severity } \\
\text { (Nadir) }\end{array}$ & $15 \pm 13$ & $\begin{array}{c}24 \pm 9 \\
P=0.19 n=5\end{array}$ & $22 \pm 6$ & $\begin{array}{c}74 \pm 27 \\
P=0.09 n=4\end{array}$ & $16 \pm 4$ & $P=0.06 n=9$ \\
\hline \multicolumn{7}{|c|}{ CFVs and low flow (pooled) } \\
\hline $\begin{array}{l}\text { Severity } \\
\text { (Nadir) }\end{array}$ & $32 \pm 9$ & $\begin{array}{c}49 \pm 13 \\
P=0.03 n=9\end{array}$ & $35 \pm 10$ & $\begin{array}{c}80 \pm 18 \\
P=0.01 n=8\end{array}$ & $33 \pm 6$ & $\begin{array}{c}64 \pm 11 \\
P=0.001 n=17\end{array}$ \\
\hline
\end{tabular}

Frequency, number of CFVs per $30 \mathrm{~min}$; severity, lowest coronary blood flow detected during CFVs or persistent low flow; total, pooled data for both serotonin or $\mathrm{TXA}_{2}$ receptor antagonists. 




Figure 6. Aortic pressure, and phasic and mean coronary blood flows are shown from an unsedated, closed-chest dog on postoperative day 3 . At rest, the coronary blood flow was stable and without CFVs. 5 min after the initiation of treadmill exercise at $1 \mathrm{mph}$, a series of CFVs was observed. With continued exercise, the coronary flow decreased to virtually undetectable levels. The administration of SQ29548, a thromboxane $\mathrm{TXA}_{2} / \mathrm{PGH}_{2}$ receptor antagonist, restored coronary blood flow to $70 \%$ of control after $<1 \mathrm{~min}$.
Treatment with yohimbine. The alpha ${ }_{2}$-adrenergic receptor antagonist was administered to four dogs during exercise-induced episodes of reduced coronary blood flow (Table VII). Yohimbine (average dose $2.0 \mathrm{mg} / \mathrm{kg}$ ) reduced the frequency of exercise-induced CFVs $(9.1 \pm 1.1$ vs. $4.4 \pm 0.5)$ in two of two dogs, but did not completely prevent the occurrence of CFVs. In two dogs with persistent low flow, the addition of yohimbine to SQ29548 and LY53857 or ketanserin failed to improve coronary blood flow (average flow $5 \pm 2 \%$ control). Yohimbine did not cause any significant changes in heart rates or blood pressures in these awake, exercising dogs.

\section{Discussion}

Previously, we and others speculated that platelet aggregation at sites of coronary artery stenosis and endothelial injury may play an important role in certain coronary occlusive syndromes in man (1-8). In this study, we used a well-established animal model of in vivo platelet aggregation to test the effect of treadmill exercise or ventricular pacing on the induction of platelet aggregation in stenotic canine coronary arteries with endothelial injury. The results indicate that moderate treadmill exercise in dogs with coronary stenosis and injured endothelium results, in most cases, in severe reductions in coronary

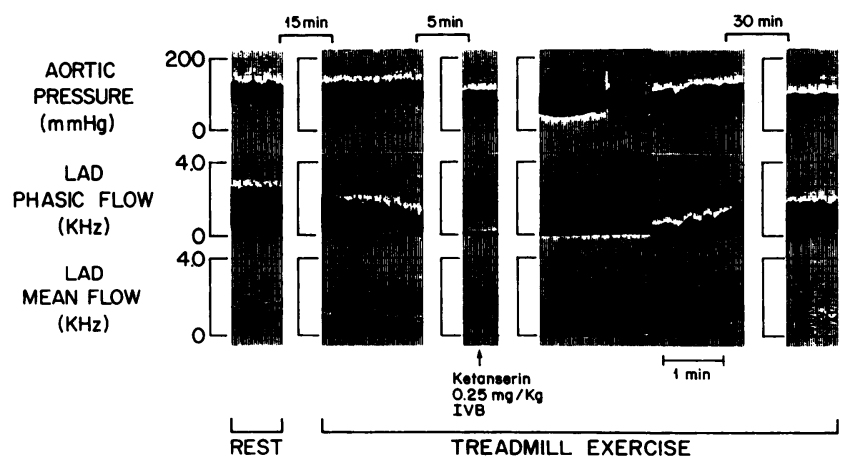

Figure 7. This recording shows the effect of the serotonin receptor antagonist, ketanserin, on exercise-induced low coronary blood flow. The aortic pressure and coronary blood flow is shown. The coronary blood flow is stable at rest. 15 min after beginning exercise, coronary blood flow slowly decreased. $5 \mathrm{~min}$ later, coronary blood flow approached zero. Ketanserin $(0.25 \mathrm{mg} / \mathrm{kg}$ intravenous bolus), a serotonin receptor antagonist, restored coronary blood flow while exercise continued. artery blood flow. Initially, the coronary obstruction occurs in a cyclic pattern of gradual flow reduction followed by abrupt restorations of coronary flow. Progression from intermittent CFVs to persistent low flow was observed in 8 of 11 dogs.

Complex neurohumoral and hemodynamic alterations occur during treadmill exercise that may contribute to the induction of platelet activation. Previous studies from other laboratories have indicated that increased heart rates and associated shear rates may be instrumental in promoting intracoronary platelet aggregation (31). In a group of patients with significant coronary disease, Lewy et al. demonstrated a


Figure 8. $(A)$ The frequency of CFVs before and after treatment with either a serotonin receptor antagonist or $\mathrm{TXA}_{2}$ receptor antagonist is shown. There was a marked decrease in the frequency of CFVs after treatment with either agent. $(B)$ The change in mean coronary blood flow after administration of a serotonin receptor antagonist (ketanserin, $n=3$ or LY53857, $n=6$ ) in dogs with exercise-induced reductions in coronary blood flow is shown. There was no statistical difference between coronary blood flows before treatment with either agent ( $32 \pm 9$ vs. $35 \pm 10 \%$ control, $P=\mathrm{NS}$, unpaired $t$ test). Coronary blood flow was significantly higher after treatment with a serotonin ( $49 \pm 13 \%$ control, $P=0.03$ ) or $\mathrm{TXA}_{2}$ receptor antagonist $(80 \pm 18 \%$ control, $P=0.01$ ). Hatched bars, before treatment; filled bars, after treatment. 
Table VII. Effect of Treatment with Yohimbine on Exercise-induced Reductions in Coronary Blood Flow in Dogs with Coronary Stenoses

\begin{tabular}{|c|c|c|c|c|c|c|c|c|}
\hline & Heart rate & AOS & AOD & Phasic peak & Phasic nadir & Mean peak & Mean nadir & Frequency of CFVs \\
\hline & beats/min & \multicolumn{2}{|c|}{$m m H g$} & & \multicolumn{2}{|c|}{ \% control } & & \\
\hline \multicolumn{9}{|c|}{ Yohimbine (average dose $2.0 \mathrm{mg} / \mathrm{kg})(n=4)$} \\
\hline Before & $152 \pm 36$ & $124 \pm 7$ & $85 \pm 3$ & $55 \pm 28$ & $31 \pm 13$ & $57 \pm 28$ & $32 \pm 14$ & $\begin{array}{c}9.1 \pm 1.1 \\
0.05\end{array}$ \\
\hline After & $154 \pm 34$ & $118 \pm 8$ & $83 \pm 3$ & $56 \pm 28$ & $33 \pm 14$ & $58 \pm 28$ & $36 \pm 14$ & $4.4 \pm 0.5$ \\
\hline
\end{tabular}

Before/after, treatment effect; AOS, systolic blood pressure; AOD, diastolic blood pressure; Phasic peak/nadir, highest and lowest phasic coronary blood flow recorded before and after treatment; frequency, number of CFVs per $30 \mathrm{~min}$. During cases of persistent low flow, the same values were recorded for peak and nadir flows; $P<0.05$ significant, paired $t$ test.

marked efflux of $\mathrm{TXB}_{2}$, the stable metabolite of $\mathrm{TXA}_{2}$, from the coronary sinus after atrial pacing (32). In animals, atrial pacing has been shown to potentiate the adhesion of platelets at sites of canine coronary stenosis as evidenced by microscopic assessment (33). In this study, ventricular pacing, at rates comparable to those observed during treadmill exercise, resulted in demonstrable reductions in coronary artery blood flow in only one dog. Although the formation of small, hemodynamically insignificant platelet aggregates might go undetected in our model, this study suggests that in awake, unsedated dogs, ventricular pacing does not play a dominant role in promoting platelet aggregation at sites of coronary stenosis.

Treadmill exercise, in the same dogs, resulted not only in increased heart rates, but also increased systolic blood pressures and increased plasma catecholamine levels. In vitro, epinephrine is known to be an important promotor of platelet activation, particularly in synergism with other agents, including ADP (34), thrombin (35), and/or collagen (36). The effect of epinephrine on platelet activation is thought to be mediated through alpha $a_{2}$-adrenergic receptors on the platelet surface membrane (37). Occupancy of the alpha $_{2}$ receptors by epinephrine results in an increase in intracellular ionized $\mathrm{Ca}^{2+}$ which is postulated to decrease the threshold for activation (38). Epinephrine may also induce the appearance of fibrinogen receptors on the platelet surface membrane that may play an important interplatelet adhesive function (39). Thus, increases in systemic epinephrine concentration may have contributed to platelet aggregation during exercise by stimulating alpha $_{2}$ receptors on platelets and/or by contributing to vasoconstriction at sites of coronary artery stenosis and endothelial injury.

Using an animal model, it has been reported that epinephrine infusion exacerbates the severity of spontaneous CFVs in dogs with coronary artery stenoses (40). Furthermore, epinephrine infusion has been shown to restore CFVs after their successful abolition with cyclooxygenase inhibition (20), thromboxane synthesis inhibition (41), or serotonin receptor antagonism (41). In this study, treadmill exercise resulted in the development of CFVs in all dogs, although not during every exercise period. Although yohimbine did not completely abolish exercise-induced reductions in coronary blood flow in any of four dogs, yohimbine did reduce the frequency of cyclic flow variations by nearly $50 \%$. Other laboratories have reported the limited efficacy of yohimbine in abolishing CFVs in anesthetized dogs (42). In summary, the data from this study suggest that increases in circulating epinephrine may increase the likelihood of developing CFVs, but that alpha ${ }_{2}$-adrenergic receptor antagonism does not consistently prevent the occurrence of exercise-induced coronary blood flow reduction in this model. It is possible that platelet agonists other than epinephrine are of equal or greater importance locally at the site of coronary stenosis and endothelial injury.

Both treadmill exercise and pacing were associated with an increase in coronary blood flow before the onset of CFVs or low flow. It is possible that increased wall shear stress or turbulence may contribute to the development of CFVs.

In experiments from our laboratory, serotonin and $\mathrm{TXA}_{2}$ have been shown to cooperate in the mediation of CFVs in anesthetized, open-chest dogs with coronary stenoses (9-14). We have previously reported that serotonin receptor inhibition with ketanserin or LY53857 (9-11) or that inhibition of thromboxane synthesis (12), with dazoxiben, or TXA $\mathrm{A}_{2}$ receptor activation, with SQ29548 (13), abolishes CFVs in most dogs. The combination of serotonin and $\mathrm{TXA}_{2}$ receptor antagonism abolishes CFVs in virtually every case in anesthetized dogs (11). We have also shown in anesthetized dogs that vasoconstriction resulting from the release of $\mathrm{TXA}_{2}$ and/or serotonin by activated platelets may contribute to decreased coronary blood flow (43) and that $\mathrm{TXA}_{2}$ and serotonin receptor antagonists prevent the coronary artery vasoconstriction associated with cyclic coronary flow alterations occurring in the anesthetized, open-chest $\operatorname{dog}(43)$. In our previous studies, we have not been able to demonstrate that $\mathrm{TXA}_{2}$ or serotonin exert coronary vasoconstrictor effects at sites other than where platelets attach in excess numbers, i.e., at the coronary stenosis and at adjacent sites where endothelial injury coexists (43). Furthermore, $\mathrm{TXA}_{2}$ and serotonin receptor antagonists generally prevent cyclic flow alterations and coronary vasoconstriction without altering systemic hemodynamics importantly. Our data suggest that $\mathrm{TXA}_{2}$ and serotonin cause CFVs primarily by promoting platelet aggregation and coronary vasoconstriction at the coronary stenosis and immediately adjacent sites $(9-13,43)$. The treatment of CFVs was substantially more successful than the treatment of persistent low coronary flow, suggesting a more durable obstruction at or near the site of coronary stenosis during periods of persistent low flow.

In summary, the evidence from the current study supports the following conclusions: (a) treadmill exercise in dogs promotes the development of CFVs in awake, closed-chest dogs with coronary stenosis and endothelial injury; $(b)$ ventricular pacing does not consistently cause coronary blood flow reduction in the same model; and $(c)$ serotonin and TXA $A_{2}$ are im- 
portant mediators of CFVs in this model. Alpha 2 -adrenergic receptor activation by circulating epinephrine may contribute to the aggregation of platelets in exercising dogs.

\section{Acknowledgments}

We wish to express our sincere gratitude to Lacy Hill Eidt and Mary Hammond for their assistance in the preparation of this manuscript and to Patricia Pastor for assistance with the statistical analyses.

This work was supported in part by National Heart, Lung, and Blood Institute Ischemic Specialized Center of Research HL-17669 and the Moss Heart Fund, Dallas, TX.

\section{References}

1. Willerson, J. T., L. D. Hillis, M. Winniford, and L. M. Buja. 1986. Speculation regarding mechanisms responsible for acute ischemic heart disease syndromes. J. Am. Coll. Cardiol. 8:245-250.

2. Willerson, J. T., W. B. Campbell, M. Winniford, J. Schmitz, P. Apprill, B. G. Firth, J. Ashton, T. Smitherman, L. Bush, and L. M. Buja. 1984. Conversion from chronic to acute coronary artery disease: speculation regarding mechanisms. Am. J. Cardiol. 54:1349-1354.

3. Folts, J. D., K. Gallagher, and G. G. Rowe. 1982. Blood flow reductions in stenosed canine coronary arteries: vasospasm or platelet aggregation? Circulation. 65:248-255.

4. Fitzgerald, D. J., L. Roy, F. G. Catella, and G. A. Fitzgerald. 1984. Platelet aggregation in unstable coronary disease. N. Engl. J. Med. 315:983-989.

5. Fuster, V., and J. H. Chesebro. 1986. Mechanics of unstable angina. N. Engl. J. Med. 315:1023-1025.

6. Aiken, J. W., R. J. Shebuski, and R. R. Gorman. 1980. Blockage of partially obstructed coronary arteries with platelet thrombi: comparison between its prevention with cyclooxygenase inhibitors versus prostacyclin. Adv. Prostaglandin Thromboxane Res. 7:663-669.

7. Aiken, J. W., R. R. Gorman, and R. J. Shebuski. 1979. Prevention of blockage of partially obstructed coronary arteries with prostacyclin correlates with inhibition of platelet aggregation. Prostaglandins. 17:483-494.

8. Hirsh, P. D., L. D. Hillis, W. B. Campbell, B. G. Firth, and J. T. Willerson. 1981. Release of prostaglandins and thromboxane $A_{2}$ in the coronary circulation in patients with ischemic heart disease. $N$. Engl. J. Med. 304:685-691.

9. Bush, L. R., W. B. Campbell, K. Kern, G. D. Tilton, P. Apprill, J. Ashton, J. Schmitz, L. M. Buja, and J. T. Willerson. 1984. The effects of alpha-adrenergic and serotonergic receptor antagonists on cyclic blood flow alterations in stenosed canine coronary arteries. Circ. Res. 55:642-652.

10. Ashton, J., C. R. Benedict, C. Fitzgerald, S. Raheja, A. Taylor, W. B. Campbell, L. M. Buja, and J. T. Willerson. 1986. Serotonin as a mediator of cyclic flow variations in stenosed canine coronary arteries. Circulation. 73:572-578.

11. Ashton, J., M. L. Ogletree, I. M. Michel, P. Golino, J. M. McNatt, A. L. Taylor, A. Raheja, J. Schmitz, L. M. Buja, W. B. Campbell, and J. T. Willerson. 1987. Cooperative mediation by serotonin $\mathrm{S} 2$ and thromboxane $\mathrm{A} 2 /$ prostaglandin $\mathrm{H} 2$ receptor activation of cyclic flow variations in dogs with severe coronary stenoses. Circulation. 76:952-959.

12. Bush, L. R., W. B. Campbell, L. M. Buja, G. D. Tilton, and J. T. Willerson. 1984. Effects of the selective thromboxane synthetase inhibitor dazoxiben on variations in cyclic blood flow in stenosed canine coronary arteries. Circulation. 69:1161-1170.

13. Ashton, J., J. M. Schmitz, W. B. Campbell, M. L. Ogletree, S. Raheja, A. L. Taylor, C. Fitzgerald, L. M. Buja, and J. T. Willerson. 1986. Inhibition of cyclic flow variations in stenosed canine coronary arteries by thromboxane $\mathrm{A} 2$ /prostaglandin $\mathrm{H} 2$ receptor antagonists. Circulation. 74:(Suppl. II):2-18 and Circ. Res. 59:568-578.
14. Schmitz, J. M., P. G. Apprill, L. M. Buja, J. T. Willerson, and W. B. Campbell. 1985. Vascular prostaglandin and thromboxane production in a canine model of myocardial ischemia. Circ. Res. 57:223231.

15. Ware, J. A., M. Smith, and E. W. Salzman. 1987. Synergism of platelet-aggregating agents: role of elevation of cytoplasmic calcium. $J$. Clin. Invest. 80:267-271.

16. Ardlie, N. G., H. A. Cameron, and J. Garrett. 1984. Platelet activation by circulating levels of hormones: a possible link in coronary heart disease. Thromb. Res. 36:313-322.

17. Laustiola, K., E. Seppala, T. Nikkari, and H. Vapaatalo. 1984. Exercise-induced increase in plasma thromboxane $B_{2}$ in healthy men: influence of beta-adrenergic blockade. J. Cardiovasc. Pharmacol. 6:449-454.

18. Green, L. H., E. Seroppian, and R. I. Handin. 1980. Platelet activation during exercise-induced myocardial ischemia. $N$. Engl. $J$. Med. 302:193-197.

19. Strauss, W. E., G. Cella, A. F. Parisi, and A. A. Sasahara. 1985. Serial studies of platelet factor 4 and beta-thromboglobulin during exercise in patients with coronary artery disease. Am. Heart J. 110:293-299.

20. Folts, J. D., E. B. Crowell, Jr., and G. G. Rowe. 1976. Platelet aggregation in partially obstructed vessels and its elimination with aspirin. Circulation. 54:365-370.

21. Folts, J. D., K. Gallagher, and G. G. Rowe. 1977. Hemodynamic effects of controlled degrees of coronary artery stenosis in short-term and long-term studies in dogs. J. Thorac. Cardiovasc. Surg. 73:722-727.

22. Coller, B. S., J. D. Folts, L. E. Scudder, and S. R. Smith. 1986. Antithrombotic effect of a monoclonal antibody to the platelet glycoprotein IIb/IIIa receptor in an experimental animal model. Blood. 68:783-786.

23. Hartley, C. J., H. G. Hanley, R. M. Lewis, and J. S. Cole. 1978. Synchronized pulsed doppler blood flow and ultrasound dimension measurement in conscious dogs. Ultrasound Med. Biol. 4:99-110.

24. DeClerck, F., J. David, and P. Janssen. 1982. Inhibition of 5-hydroxytryptamine-induced and amplified human platelet aggregation by ketanserin (R41, 468), a selective 5-HT2-receptor antagonist. Agents Actions. 12:3.

25. Meuleman, T. R., D. C. Hill, J. D. Port, T. H. Stanley, N. L. Pace, and S. F. Mohammad. 1983. Ketanserin prevents platelet aggregation induced pulmonary vasoconstriction. Crit. Care Med. 11:606611.

26. Van De Water, A. L., L. Wouters, R. Xhonneux, and S. Reneman. 1985. Cardiovascular effects of ketanserin in closed-chest anesthetized dogs. Arch. Int. Pharmacol. Ther. 275:267-277.

27. Cohen, M. L., W. Colbert, and L. A. Whittnauer. 1985. Receptor specificity of the $5 \mathrm{HT}_{2}$ receptor antagonist (LY53857). Drug Dev. Res. 5:313-321.

28. Cohen, M., R. W. Fuller, and K. D. Kurz. 1983. LY53857, a selective and potent serotonergic $\left(5-\mathrm{HT}_{2}\right)$ receptor antagonist, does not lower blood pressure in the spontaneously hypertensive rat. J. Pharmacol. Exp. Ther. 227:237-333.

29. Ogletree, M. L., D. N. Harris, R. Greenburg, M. F. Haslanger, and M. Nakane. 1984. Pharmacological action of SQ29, 548, a novel selective thromboxane antagonist. J. Pharmacol. Exp. Ther. 234:435.

30. Goldberg, M. R., and D. Robertson. 1983. Yohimbine: a pharmacological probe for the study of the alpha $_{2}$ receptor. Pharmacol. Rev. 35:143-180.

31. Turitto, V. T., and H. R. Baumgartner. 1979. Platelet interaction with subendothelium in flowing rabbit blood: effect of shear rate. Microvasc. Res. 17:38-54.

32. Lewy, R. I., L. Weiner, P. Walinsky, A. M. Lefer, M. J. Silver, and J. B. Smith. 1980. Thromboxane release during pacing induced angina pectoris: possible vasoconstrictor influence on the coronary vasculature. Circulation. 61:1165-1171. 
33. Walinsky, P., A. M. Lefer, P. Frasca, and W. Santamore. 1984. Potentiation of coronary vascular platelet adhesion by atrial pacing in the presence of arterial stenosis in dogs. J. Am. Coll. Cardiol. 3:12521255.

34. Mills, D. C. B., and G. K. Roberts. 1967. Effects of adrenaline on human blood platelets. J. Physiol. (Lond.). 193:443-453.

35. Steen, V. M., and H. Holmsen. 1985. Synergism between thrombin and epinephrine in human platelets: different dose response relationships for aggregation and dense granule secretion. Thromb. Haemostasis. 54:680-683.

36. Beatty, C. H., C. F. Howard, Jr., and V. Caruso. 1986. Potentiation with epinephrine of macaque platelet aggregation by other agonists: implications for study on human atherosclerosis. Thromb. Res. 41:447-458.

37. Grant, J. A., and M. C. Scrutton. 1979. Novel alpha ${ }_{2}$-adrenoreceptors primarily responsible for inducing human platelet aggregation. Nature (Lond.). 277:659-660.

38. Owen, N. E., H. Feinberg, and G. C. Le Breton. 1980. Epinephrine induces $\mathrm{Ca}^{++}$uptake in human blood platelets. Am. J. Physiol. 239:H483-488.
39. Plow, E. F., and G. A. Marguerie. 1980. Induction of the fibrinogen receptor on human platelets by epinephrine and the combination of epinephrine and ADP. J. Biol. Chem. 255:10971-10977.

40. Folts, J. D., and K. P. Gallagher. Epinephrine-induced platelet aggregation in mechanically stenosed dog coronary arteries occurring after aspirin administration. Clin. Res. 26:231. (Abstr.)

41. Ashton, J. H., A. L. Taylor, W. B. Campbell, L. M. Buja, and J. T. Willerson. 1986. Potential interaction of epinephrine with serotonin and thromboxane $A_{2}$ in causing cyclic flow variations in severely narrowed canine coronary arteries. Circulation. 74(Suppl. II):11-18.

42. Bolli, R., T. A. Brandon, M. L. Mace, Jr., and D. G. Weilbaecher. 1985. Influence of alpha-adrenergic blockade on platelet-mediated thrombosis in stenosed canine coronary arteries. Cardiovasc. Res. 19:146-154.

43. Golino, P., J. Ashton, L. M. Buja, A. L. Taylor, J. McNatt, M. Rosolowsky, W. B. Campbell, and J. T. Willerson. 1989. Local platelet activation causes vasoconstriction of large epicardial canine coronary arteries in vivo: thromboxane and serotonin are possible mediators. Circulation. 79:154-166. 